\title{
Art Rehabilitation of Disabled People in Russian Federation
}

\author{
Alexander Yakoupov \\ Russian State Specialized Academy of Arts \\ Moscow, Russia
}

\begin{abstract}
Disabled people can also have their distinctive lives. In spite of their disabilities, many of them are firm in spirit and alway hold the hope for life. Art, as an life-saving straw, stirred up their hope for love. In Russia, the art rehabilitation of disabled people has been on the rise, thus provoked many attention on this particular group. This paper conducted a thorough research on the history and current situation of artistic programmes helping the disabled, showing confidence in this field.
\end{abstract}

\section{Keywords—art rehabilitation; the disabled; talents}

\section{INTRODUCTION}

Art plays an important role in the lives of disabled people. Perception, studying, creation of artistic forms not only widens spiritual world of a person - both spiritual and aesthetic, but also allows people with limited abilities to realize all scales of human values. In this case, we can see not only the healing role of art in the lives of disabled ones, but also many great treasures that disabled people, many of them are artistically gifted, bring to culture.

\section{Among them, there are}

- the ancient Greek poet Homer, the author of Odyssey and Iliad, who was born blind;

- the great composers: Johann Sebastian Bach, who at the age of 14 started loosing his eyesight and got completely blind by the end of his life. George Friedrich Ghendel, who in spite of his blindness, which happened to him in the middle of his life, kept actively composing and directing his music. Ludwig van Beethoven, who became deaf at the age of 28 , but kept creating melodious compositions. Antonio Vivaldi and Modest Mussorgsky who suffered epilepsy. Dmitry Shostakovich, a wonderful pianist, who had a poor eyesight and suffered from atrophic muscles;

- great writers: Miguel Cervantes, the author of Don Quixote, who lost an arm in a marine battle, Theodor Dostoyevsky, who suffered from epilepsy;

- great artists: Leonardo da Vinci who suffered from cerebral paralysis, Boris Kustodiev, who was painting in a wheelchair;

- the great French actress Sarah Bernard, who lost a lot as a result of a trauma, but it didn't prevent her from creating tragic images of women, which created the whole epoch in the history of theatre;

- Maria Callas, an outstanding opera singer of XX century, who was short-sighted, which didn't prevent her form acting on the stage and playing in films;

- Andrea Bocelli, Steve Wonder and Ray Charles - the world-famous modern music performers, who were born blind.

This list of famous creators, who suffered different kinds of disabilities, can be continued.

\section{THE HISTORY OF CREATION OF REHABILITATION INSTITUTIONS IN RUSSIA AND THE CURRENT SITUATION.}

Specialized education for children appeared in Russia in 1897, when the Empress Maria Fedorovna established a special institution. It was like children's orphanages.

In 1806, thanks to the efforts of V. Guyi in Pavlovsk, the first experimental school for deaf and mute pupils was open. Later in 1807 - a specialized school for the blind was also formed..

Guyi considered it important to teach disabled pupils:

"we should give blind people an opportunity to study in order to save them from the burden of laziness, which creates bad habits and vices, we should unite blind people with work, useful both for the society and for themselves";

"we should give talented people from well-off families a chance to do intellectual work in order to make them independent and to help them to start self-study and selfdevelopment";

V. Guyi believed that the results of educating a blind person who was called incapable of sciences and crafts, will become a good proof of human beings' educational potential for young people.

In 1854, in Riga, a sign language teacher Friedrich Pliatz founded the first mentally challenged and epileptic students institution in the Russian Empire, which aimed not only to heal, but also to teach using E. Segan's system. Pliatz's widow, who headed the organization in 1864, used successfully the systems created by Ferghel and Georgens. Afterward, such institutions started to appear in St. Petersburg (E.K. Gracheva's school, Malyarevsky's school) and also in Moscow (M.P. Postovskaya's classes). The greatest Russian correction teachers of that time were A.I. Graborov, L.K. Shlegher, K.N. Kornilov. In 1908 V.P. Kashenko opened "a sanatorium- 
school for defected children".

At the beginning of the 20th century, there were about four and a half thousand of charity organizations and six and a half thousands organizations of social support keeping children with developmental defects in Russia. By 1917 there were 61 schools for the deaf people, 30 institutions for the blind ones and 18 institutions for children with mental defects.

The main role of Soviet Union's educational system at that time has become education for children with limited physical opportunities and making them useful members of the society. As soon as church, which was separated from the state, lost its leading role in coordination of educational and social work with such children, special pedagogical methods became only secular. All charity organizations were closed, their activity was also prohibited.

Specialized educational institutions were under the command of the People's Commissariat, headed by A.V. Lunacharsky. In his time there appeared a notion of "mentally retarded " or "corporally defected". The first were educated in the so-called "auxiliary schools", the second - in special boarding schools. A closed boarding school became the model. A special decree of the Council of Peoples Commissars (1926) regulated the order of education for special needs of children in special institutions, the number of which has considerably decreased in comparison to that in the Pre-Revolutionary period.

Officially declared aim of specialized education was "preparation through school and labor for communally useful activity". Education in such institutions was free of charge and was funded by the state budget.

In 1950s, certain changes have happened in the system of specialized education. Both the number of specialized institutions and their kinds have increased. General school reforms contributed to it: at first - introduction of an 8-year compulsory education (1959) and later a 10-year compulsory education (1966) for all children. A special attention was now paid to development of professional skills, which allowed its graduates to find certain jobs, according to their physical conditions.

In 1980s, there appeared correction classes in some comprehensive schools, and later there appeared experimental schools for deeply mentally challenged children. So, by 1990 in the Soviet Union there were 2789 such institutions, which covered about 575 thousand students.

It was undoubtedly a great chance to get education improve the life quality of disabled children. But there existed a certain discriminative, unscientific and pedagogically-wrong division of children. Children were divided into the "taught" and "untaught" ones. The latter ones were considered to be "invalid" and "rejected" ones. Besides, there were not enough speech pathology specialists and social programs of family support was inadequate. Thus, the system, created in the Soviet Union, could not be considered to be perfect.

We have to admit that correction schools, existing now in the Russian Federation, did not create a complete system to rehabilitation children of special needs. At the same time there are very few institutions of pre-college preparation, where young people could get artistic education. Let's name them.

Specialized music school for blind and poor-sighted children in the town of Armavir was open in 1989. It is the only music school in Russia for blind or poor-sighted children, which works on typical study plans. There are 310 students now, including 110 students from Krasnodar region as well as Adygheya Republic. Since 1993 children with regular eye sight could also study there.

The principle of mixed education of regular children and special needs children is the basis for this school. Thanks to it, the problem of rehabilitation of disabled children through music can be successfully solved. Collective music playing is considered to be the most effective form of adaptation.

The problem of professional orientation is also being solved here. During 25 years of school's work, 74 students have continued their education in music schools of the country. Many of them are numerous winners of the regional and national contests and music festivals. The school graduates take part in concerts, charity activities which are held by the foundation named "World of Arts" in many countries.

Moscow rehabilitation College for disabled students was created in 1979. Students with limited hearing abilities study different kinds of applied arts here. The classes are held in specially equipped classes having multimedia. Practical workshops are held in workshops, equipped according to the needs of the company where the student works. Students also have a chance to have practice in different companies.

Highly qualified specialists work in the College, among them there are 3 M.A.s, 27 teachers of the highest degree, among them 5 are members of the Artist's Union of Russia. The main principles of education lie in development of artistic and intellectual abilities, desire for self-expression and achievement of realistic results in practical activity.

International college for deaf students rehabilitation (Pavlovsk town of Leningrad region). In 1965 a unique educational institution appeared: a college of Leningrad technical rehabilitation center of All-Russian Deaf Association. Its creator was Josef Heylman, son of deaf parents. The creative-artistic atmosphere in his family influenced Heylman's development. After the war he established a studio in Leningrad, which included young people from all the Soviet Union. Thanks to his organizational skills, the common painting studio later turned into a rehabilitation center. It not only educated students, but also had its own manufacturing base, which had many state orders.

Leningrad Rehabilitation Center of All-Russian Deaf Association has built houses for its members and provided its graduates with work. In its publishing house, there were printed books, sign language dictionaries, methodology manuals. Young disabled people managed to get a good education in different departments and got different professions such as an artist, an accountant, a sign language translator, a lawyer, a radio engineer, etc. The most talented and oriented students got higher education and got great 
success in life.

Kursk music boarding college for the blind is Russia's only federal educational institution for comprehensive music education for the blind youths. Its history is also very remarkable: it was firstly founded as a music school for the military men in 1945, who got blind during WWII, but later transformed into a boarding school for the common blind people. It has existed as a college for the last 10 years.

During its activity the college helped to start a music career for over 2000 people. They later became leaders of different music groups, philharmonic soloists. "Instrumental performance", "Vocal singing", "Choir conducting" are the subjects that are taught at the college.

Russian State Specialized Academy of Arts exists in Moscow since 1990. It began its activity as a structural division of All-Russian Center for Disabled Rehabilitation.

The Center has been created on the initiative of social organizations and famous culture activists of the Soviet Union with the support of the government. In November of 1990, a Decree of the Ministry of Culture №340 “About the creation of Specialized Institute of Arts of All-Russian Center of Rehabilitation of Disabled People". On Nov. 161991 the Code of SSIA has been registered and a building was found (Rezervny lane, 10/12).

In December 1991 the Center came into jurisdiction of the Ministry of Culture of the Russian Federative Socialist Republic and was given the name as "Russian International Center of Creative Rehabilitation of Disabled Ones" and the Institute kept its name. However, the Institute did not take effect because of the changes in legislation. In accordance with the decree of the Head of the Government of Russian Federation on Jan 15th in 2004. №55 Russian Center of Creative Rehabilitation of Disabled Ones of Ministry of Culture was transformed into Federal State Educational Institution of Higher Professional Education "State Specialized Institute of Arts".

During all years of its existence, many people and organizations took part in creation of the Institute. Among them are: the Foundation of Social Inventions of the USSR, All-Russian Disabled Association, the Soviet Foundation of Charity and Health, the Committee of Veterans and Disabled People of the Supreme Council of USSR, the Soviet Children Foundation, the Academy of Pedagogical Sciences of USSR, the UNESCO Commission in the USSR, Academy of Arts of USSR, Composer's Union of RSFSR, Cinematography Union of USSR.

Famous people of Russia - Nikolay Gubenko, Vladimir Etush, composer Alexandra Pakhmutova, poet Nikilay Dobronravov, cinema playwright Rustam Ibragimbekov, theatre teachers-spouses Albert Mekke and Olga Romanovskaya contributed greatly to the creation of the Center and the Institute.

The main activity of the Academy nowadays is the teaching of creative professions for people of limited abilities. These specifics make this institution unique not only in Russia, but also in the world.
There are three departments at the Academy, namely, musical, theater and arts. At present there are highly qualified teachers working, among them there are famous activists of Russian art: people's artists of RF Karelskih, Lomonosov, Lisovsky, actors Persiyanov, Brodskaya-Karelina, Peterson, Senin, Sidorov, Sorokin, members of Russian Academy of Arts Oleg Loshakov and Igor Polienko, famous artists of Russia Bolotskih, Komaov, Masters of Arts Imhanitsky, Filatova, Berlianchik, etc. The rector of RSSAA from 2011 is a respected arts' activist, Arts Doctor Professor Alexander Yakoupov.

During 20 years of its existence this higher educational institution has accumulated a great experience of work with gifted creative disabled students. Its equipment base is enough to keep educational process going on smoothly. Academic classes are equipped with modern devices that are necessary to have classes. There are computer classes, sound recording studio, linguistic studios. There are also 150 thousands of recordings and over 100 thousands of reproductions. There is a library with paper and digital funds, a lot of texts and notes coded by Brail system. There are large and small concert halls at the Academy, theater performances hall and an educational opera house.

RSSAA is a radically new type of inclusive educational institution, where disabled students are taught in accordance with the highest standards of professional institutions of Russian Federation. To be completely realized it is necessary:

- to have a highly experienced professional teaching staff, which has a great experience of work with disabled ones;

- great achievements in the area of preparation of specialists in different arts;

- to have a rich and successful creative life;

- to have a modern technical base in order to provide tuition process.

Thus, RSSAA has real chances to become a leader of professional cultivation of young people with limited abilities into different arts specialists.

\section{MethodologicAl BASES OF PROFESSIONAL EDUCATION OF DISABLED PEOPLE AS DIFFERENT FORMS OF ARTS SPECIALISTS}

During the last decades, a unique school of artistic education for people with limited abilities has been created in Russian Specialized Academy of Arts. Professorial-tutorial staff of the Academy has gained a great experience of work on the basis of methodological principle of early professional orientation and personal involvement into artistic activity.

It is important for a student from his first days of studies at RSSAA not only to show his artistic potential, but also to get individual support in realization of his intentions. At the same time a notion of "social independence" of a person does not only allow him to feel himself free, but also to overcome diseases both physically and mentally.

Special methods and programs have been developed at RSSAA to adapt poor-sighted, blind, poor-hearing and deaf students to reality. 
Here are the forms of professional education for the handicapped at the Academy:

- blind and poor-slighted people get higher musical education, which includes a wide scope of specializations: instrumental performing, musical-theatrical art, music sound acoustic and a stage actor;

- deaf and poor-hearing students become dramatic actors;

- deaf and wheel-chaired students specialize in arts, graphics and design.

Students' numerous achievements in different festivals and competitions prove that Russia holds a leading position in the sphere of creative artistic education of people of special needs . Here are some bright examples.

Accordion player Fidan Akhmedianov (2010 graduate) has become a laureate of eight prestigious creative competitions, including: All-Russian Roland V-Accordion Festival (3-rd place, 2010), a Competition of musical performers in the Czeche Republic (1-st place, 2012), The Pearl of Kuban' Competition (1st prize, 2007), Young Wonders Competition (annual winner from 2006 to 2009), Anatoly Belyaev Prize Competition (1st prize, 2007), Lanciano Prize (Italy, 2nd place, 2009), Libertango Competition (Italy, 2009, 3rd place).

Pianist Vitaly Kalitsky has become a prize-winner of four competitions: Paderovsky Music Competition (Poland, Lublin, 3rd prize, 2004), Young Music Performers Competition (Russia, Kursk, 2nd place, 2004), Young Performers' Competition (Czech Republic, Prague), Paderevsky Young Performers Music Competition (Poland, Lublin, 1st place, 2007), The Laureate of Concert Masters International Competition, The Stars of Big Cities (Russia, Moscow, 2013), Laureate of Concert Master of the 1st International Competition of youth festival Artistic Blitz-Tournament (Russia, Moscow, 2013).

Pianist Elena Koukharenko became a laureate of international contests three times. One of Blind Musicians' Contest in Kursk (Grand Prix, 2010), one of Prague International Contest in 2011 (1st prize) and one of Festos Contest as a performer of classic instrumental music, and also as a bard singer.

Over $90 \%$ of Academy graduates have found jobs and are working in different professions in different organizations (including RSSAA). Some graduates (Vitaly Kalizky, Olesya Grinko, Olga Golubeva, Svetlana Lysenko, Dmitry Bogatov, Dmitry Borodaev, etc) continued their education in postgraduate and internship courses at the Academy.

A unique Opera theatre for disabled people has been created at the Academy (artistic director Alexander Yakoupov).

Viva Opera festival is held at the Academy annually, where Stone Guest by Dargomyshsky, Yolanda by Tchaikovsky, A Husband behind the Door by J. Offenbach have successfully been represented.

Mimics and Gesture Nedoslov Theatre raises great public interest from 2003. The participants of the project are talented young deaf and poor-hearing actors, who graduated from theatrical department. Theatrical performances are oriented both to the hearing and deaf viewers. Nedoslov performs regularly in Moscow, tours Russia and participates in students and professional theatrical contests in Russia (Pro-Theatre, Podium, Golden Knight, Theatrical Golden Heart) and the USA (VSA, International Sign Language Festival, Canada (Abilities Festival in Toronto). In the repertoire of the theater there are the following performances: Everybody has Wings, Hand-made, The Touch, A Just Outlaw, Be Careful with a Tender Heart, No Right for an Angel.

Together with Moscow State Duma and Music Quarter Foundation, RSSAA holds International Paralympic Festival. It is held for 5 years at Russian Army Theater, at Luzhniki, etc. Talented people with disabilities from all Russia and a number of other countries (Argentina, Italy, Spain, China) take part in this festival. All genres of art are represented at the festival: soloists, choirs, ensembles, orchestras, dance groups, collective orchestra of people's instruments, mainly consisting of RSSAA students. About six thousand spectators were gathered by the last festival, many important people came, including Vice Premier Olga Golodets.

RSSAA organizes regular exhibitions where pictures and works of its students are exhibited. Exhibitions are held in specialized correction institutions, beginning from 2006 at Central House of Artists, Russian Academy of Arts.

RSSAA is holding important methodological and scientific work on accumulation of unique pedagogical experience. The Centre of the Studies of the Problems of Artistic Rehabilitation of Disabled People studies, generalizes this experience and publishes its results.

\section{Acute Problems of Education of Disabled People AND ITS SOLUTION}

Here are the following problems of inclusive education of students with disabilities:

Foreign countries' experience shows that it is possible to create the necessary conditions for education of disabled ones in common institutions. But there are two problems: 1) lack of training of tutors to work with special disabled students; 2) absence of such specialists everywhere

So, here exists a problem of specialist's training at schools and the perspective of creation of branches of RSSAA in different regions of Russian Federation. It is necessary to create specializations in normal universities and to cultivate more qualified staff through post-graduate training.

Every year the number of children with special needs increases (in 2013 the number was about 650 thousand). It is necessary to build a multi-component system of education and rehabilitation, so is emphasis on the role of art in this process. It will contribute to efficient rehabilitation of children with special needs. Thus, music and arts schools, already existing in the Russian Federation (about 6 thousand) and 157 colleges could contribute to the task of social-cultural rehabilitation of the handicapped. 
There is a problem facing the modernization of already existing and the creation of the new computer technologies, adjusted to people with special needs. It is necessary to create special equipments for the blind people by means of transformation of text information into the voice and vice versa. Special devices should be created, which allow typing texts (including notes) by Brail system. It is acute to create mobile devices, allowing to facilitate communication between the lecturer and the deaf listener, which is being fulfilled now with the help of sign language translators. However, this process is rather expensive and doesn't have enough specialists.

There's a need to adjust library work to the needs of the handicapped. It can be solved by acquisition of ultra-modern expensive computers, equipped with Brail system, what will allow people with sight problems to get information.

The problem of optimization of publishing activity. It is caused by a large need of blind students to have special editions by Brail. It is necessary to increase topics of RSSAA as a leading institution, taking into consideration the needs of the students.

There's a problem of widening the scope of educational services in the area of arts for the people with mental problems (autism syndrome). RSSAA experience has proved that such problems cannot be an obstacle for artistic achievements.

There's still an open question of usage of "pirate" programs, which hasn't by now found an official solution. According to Marrakesh agreement, there should be an unlimited access to any kind of information for the invalids, but this agreement has neither reached to the people nor to the information owners.

The problem of young people's leisure, who have no access to different entertainment institutions. Handicapped rehabilitation much depends on their free communication in the young environment. The perspective of creation of cultural-healing centers for the handicapped.

There is a problem of centralization of employment of disabled people, with artistic education. It is possible, for example, to create several groups of deaf actors at dramatic schools. There can be groups of deaf artists, introduction of extra places in the orchestras, where people with sight and hearing problems could work.

And, finally, there's a need to expand RSSAA experience to provide psychological help to the disabled ones and to use art therapy in the complex means of professional rehabilitation.

\section{CONCLUSION}

The perspectives of development in Russian Federation of specialized education for people with special needs.

In order to exclude chances of a kind of reservations for the disabled ones and taking specifics of work with people with special needs into consideration, RSSAA was created as an institute of mixed education. The idea of inclusive artistic education is considered to be unique, perspective and efficient.
Creation of work environment for the handicapped and providing them with educational process modern methodology has made Russian State Specialized Academy of Arts a unique institution.

Taking into consideration all the above, it is necessary to consider the issue of creating a complete system of rehabilitation and professional preparation of disabled students in the sphere of arts by the creation on the basis of RSSAA Federal Specialized Centre for Gifted Children and Youth with Special Needs.

The Center should include:

Specialized boarding school of arts

Russian State Specialized Academy of Arts with two residences (for the wheel-chaired and for poor-sighted students)

a cultural-healing center, including:

Theatre - exhibition hall to place an Opera studio, theatre of mimics and gesticulation, specialized choreography studio for wheel-chaired ones.

\section{Art gallery.}

Gym.

Fitness center.

Winter garden.

In the future, RSSAA branches can be open in seven Federal Districts of Russian Federation. The Academy has all the opportunities to provide them with methodological help. It will be a contribution of the Academy into the System of Specialized Professional Training of Gifted Youth.

A positive example may be taken from the successful Sochi Paralympic competition. Our sportsmen have proved that even disabled ones can win.

Taking into consideration all the accumulated experience, this project has all the chances to become the world leader in the area of artistic education.

\section{REFERENCES}

[1] Andreykin A. The role of modern society for the hearing and poorhearing teenagers. /New Ways of Solution of Children's Disability by Means od Arts \& Culture. Moscow, 2001.

[2] Indovel L. For the wheel-chaired \& the ones beside them. Perm, Zdravstvuite, 1995.

[3] Blind musicians-performers of Russia. Moscow, Homer, 2001.

[4] Loukianchikova L. Chaburina I. Resourses of Social-Cultural Work. Experimental Practice of the centre of Artistic Rehabilitation of Teenagers "Pollux" / New Ways of Solution of Children's Disability by Means od Arts \& Culture. Moscow, 2001.

[5] Modzukova J. Integrative Interaction of Rehabilitation Mekhanisms/ New Ways of Solution of Children's Disability by Means od Arts \& Culture. Moscow, 2001.

[6] Modzukova J. So,e Approaches to Social-Cultural Rehabilitation/New Ways of Solution of Children's Disability by Means od Arts \& Culture. Moscow, 2001 . 
[7] Scientific-Metodological Problems of Teaching at Specialized Arts College. SSIA, 2000.

[8] Permiakova S. Social\& Cultural Rehabilitation of Blind Children in Krasnoyarsk Region. / New Ways of Solution of Children's Disability by Means od Arts \& Culture. Moscow, 2001.

[9] Social Politics \& Social Work in the Changing Russia. Edited by E.Yarskaya-Smirnova \& P.Romanov. Moscow, 2002 